\title{
EDUCAÇÃO DE JOVENS E ADULTOS NA PERSPECTIVA DA EDUCAÇÃO INCLUSIVA/ESPECIAL: O QUE ENSINAR E PARA QUÊ ENSINAR?
}

\section{Charlton Wilton Vasconcelos de Araújo}

RESUMO: A finalidade desta pesquisa foi discorrer sobre a temática da Educação de Jovens e Adultos na Perspectiva da Educação Inclusiva, a qual tem necessidade urgente de um currículo com estratégias de ensino e aprendizagens que sejam utilizados à pequeno e médio prazo na vida do educando jovem e adulto com deficiência, saberes que façam a diferença nas dificuldades e limitações que o meio impõe-lhes. Visando investigar: Quais Metodologias, Estratégias e Aprendizagens, Contribuirão para Fazer a Diferença na Vida do Educando Jovem e Adulto com deficiência na Modalidade EJA? Mediado pelos seguintes Objetivos Específicos: Relatar sobre a inclusão e aprendizagem; discorrer sobre o que, para quê e como ensinar? E, propor aprendizagens que promovam autonomia e cidadania; Neste estudo, valeu-se da pesquisa Bibliográfica e Documental, utilizando fontes da Internet para embasar os benefícios da inclusão utilizando as premissas do Currículo Funcional Natural e do Programa de Transição para Vida Ativa na escolaridade de jovens e adultos com deficiência no Ensino Fundamental e na EJA. Esses educandos com deficiência necessitam de uma aprendizagem libertadora das suas limitações de saberes, de autonomia, instigando a independência social, o letramento e a conquista social, instigando o possível, àquilo que proporcione uma vida transformadora em todas as áreas da vida.

Palavras-chave: EJA. Educando. Deficiência. Aprendizagens.

ABSTRACT: The purpose of this research was to discuss the theme of Youth and Adult Education from the perspective of Inclusive Education, which has an urgent need for a curriculum with the teaching and learning strategy that are used for the small and medium term in the life of the young student. and disabled adults, knowledge that makes a difference in the difficulties and limitations that the environment imposes on them. Aiming to investigate: What Methodologies, Strategies and Learning, Will Contribute to Make a Difference in the Life of Educating Youth and Adult with Disabilities in EJA Modality? Mediated by the following Specific Objectives: Report on inclusion and learning; exemplify learning that promotes autonomy and citizenship; and talk about what, for what and how to use it? In this study, Bibliographic and Documentary research was used, using Internet sources to support the benefits of including the Natural Functional Curriculum and the Transition to Active Life Program in the education of young people and adults with disabilities in Elementary School and in EJA. These students with disabilities in learning that frees their limitations of

${ }^{\text {I }}$ Major da Polícia Militar de Pernambuco, Bacharel em Segurança Pública pela Academia de Polícia Militar do Paudalho (APMP) e Direito pela Faculdade Cruzeiro do Sul, Especialista em Gestão Democrática pela FACINTER/UNINTER, Gerenciamento de Crises pela AVM Faculdade Metropolitana e em Ciências Jurídicas pela Faculdade Cruzeiro do Sul. Email: capswat@hotmail.com. 
knowledge, autonomy, instigating social independence, literacy and social achievement, instigating the possible, to what provides a transformative life in all areas of life.

Keywords: EJA - Educating - Disability - Learning.

\section{INTRODUÇÃO}

O presente trabalho de pesquisa se justifica pelo crescimento no número de jovens e adultos com deficiência que estão matriculados na Educação Básica do Ensino Fundamental, e não na EJA, como seria o adequado às suas faixas etária. Também pelo fato de ser mãe de um jovem de 21 anos de idade com Microcefalia, que trouxe consequências de Déficit Visual e Cognitivo severo, e está, assim como muitos, matriculado no Ensino Fundamental recebendo um aprendizado que não favorece um desenvolvimento autônomo e cidadão.

A importância acadêmica e social da referida pesquisa dá-se pela necessidade dos Sistemas de Ensino agirem em prol de uma escolarização adequada aos educandos jovens e adultos com deficiência, a terem acesso a modalidade da EJA, que é o ideal para sua idade, concomitantemente a uma aprendizagem que traga independência $e$, possivelmente, seu acesso ao mercado de trabalho.

A educação de jovens e adultos (EJA) no Brasil é uma modalidade de ensino historicamente discriminada e desprivilegiada, trabalhadores e cidadãos comuns, são negligenciados na busca do letramento, e estão incluídos numa sociedade excludente. Uma EJA que tem papel fundamental na educação de um país com altos índices de distorção idade/série. Para resolver essa demanda, precisando se adequar a necessidade de aprendizagem de um público extremamente peculiar, que já é introduzido no processo de aprendizagem com uma bagagem de saberes que precisam ser respeitado, valorizado e de uma metodologia que além de utilizar suas demandas profissionais e de vida, traga um aprendizado concreto, significativo. De acordo com o parecer $\mathrm{CNE} / \mathrm{CBE} \mathrm{n}^{\circ}{ }_{\mathrm{II}} / \mathbf{2 0 0 0}$, A EJA "representa uma dívida social não reparada com os que não tiveram acesso e nem domínio da escrita e da leitura como bens sociais, na escola ou fora dela". Essa função reparadora da EJA aos que não tiveram esse acesso na idade própria aos bens culturais contemporâneo, que é o letramento, inclui os jovens e adultos com deficiência, que na sua maioria estão em defasagem desse letramento. Quando falamos de EJA para pessoas com deficiência, falamos de algo ainda maior em termos de necessidades de

aprendizagens significativa, por ser um público, caracterizado por um aprender fazendo, com o propósito de que essas aprendizagens sejam imediatamente aplicáveis ao cotidiano, contribuindo para um aprendizado efetivo e para a autonomia desse educando. Verificou-se que o cenário atual em nosso país, é que a maioria dos educandos jovens e adultos com deficiência estão em sala regular nas escolas dos municípios, ou inseridos em EJA's que têm metodologia didática homogênea, sem 
privilegiar as necessidades dos jovens e adultos com deficiências.

Diante desse cenário, indaga-se: quais as ações, conteúdos e atividades a escola pode promover para os saberes e autonomia dos educandos jovens e adultos com deficiência no ensino fundamental e na EJA?

Destarte, o Objetivo Geral visa apresentar as possíveis soluções para a problemática: Quais Metodologias, Estratégias e Aprendizagens, Contribuirão para Fazer a diferença na vida do Educando Jovem e Adulto com deficiência na Modalidade EJA?

Portanto, a intencionalidade da referida pesquisa é que os atores envolvidos tenham pleno conhecimento da importância do seu papel na promoção de uma aprendizagem significativa para os educandos jovens e adultos da EJA e buscando ensinos que sejam transformadores de vida, proporcione ao educando fazer parte da sociedade com liberdade de escolhas e autonomia, o mais possível, de acordo com cada condição, através de aprendizagens funcionais que irão proporcionar gradativamente a plenitude do desenvolvimento global e sua, possível, inserção ao mercado de trabalho.

Para tal, foram elencados os seguintes Objetivos Específicos:

- Descrever a situação de inclusão e aprendizagem dos jovens e adultos com deficiência matriculados na EJA.

- Discorrer sobre: O que ensinar? Para quê ensinar? E, como ensinar os Jovens e Adultos com deficiência na EJA?

- Propor aprendizagens que promovam autonomia e cidadania.

Parte-se da Hipótese de que adotando a metodologia do Currículo Funcional Natural e do programa de Transição para a Vida Ativa com aprendizagens que sejam uteis e possam ser colocadas em prática de imediato

na vida dos educandos jovens e adultos, eles terão um ganho significativo dos saberes, da autonomia e da inserção social em diversos ambientes da sociedade, inclusive no profissional.

Assim, para viabilizar o teste da hipótese, realiza-se uma pesquisa de abordagem Qualitativa, de natureza Básica com objetivo de pesquisa Descritivo e Exploratório sob o método hipotético dedutivo, e realizada com Procedimentos Bibliográfico e Documental para responder à questão da problematização aqui delineada.

Portanto, nas seções dessa pesquisa verificam-se primeiramente o conceito e um breve histórico da EJA, desde os tempos do Brasil colônia, até os dias de hoje, e um breve cenário atual da EJA na perspectiva da Educação Inclusiva. Na segunda seção dar-se a conhecer algumas estratégias de ensino que podem nortear a aprendizagem de jovens e adultos com deficiências. Por fim, na última seção, um panorama das necessidades de aprendizagens práticas atuais que tenham significado e sejam colocadas em prática imediatamente. E, da motivação e participação da família nesse processo.

Ao final, conclui-se que os objetivos são atendidos e a pesquisa respondida com a 
confirmação da hipótese, indicando que se faz necessária a adoção de novas estratégias e métodos de ensino e aprendizagem para oferecer os saberes e a autonomia que os educandos jovens e adultos com deficiências que estão matriculados na EJA ou no Ensino Fundamental necessitam para transformarem as suas vidas.

\section{UM BREVE HISTÓRICO DA EJA NO BRASIL}

A Educação de Jovens e Adultos (EJA) é uma modalidade de ensino, que perpassa todos os níveis da Educação Básica do país. Essa modalidade é destinada a jovens e adultos que não deram continuidade em seus estudos e para aqueles que não tiveram o acesso ao Ensino Fundamental e/ou Médio na idade apropriada.

A Lei no 9.394, de 20 de dezembro de 1996 (Lei de Diretrizes e Bases da Educação Nacional), passa a vigorar com a seguinte redação da Lei 13.632 de o6 de março de 2018 no Art. 37: A educação de jovens e adultos será destinada àqueles que não tiveram acesso ou continuidade de estudos nos ensinos fundamental e médio na idade própria e constituirá instrumento para a educação e a aprendizagem ao longo da vida.

A Educação de Jovens e Adultos, à princípio, no Brasil era ministrada pelos jesuítas que na época eram os responsáveis pela educação no país e se dedicavam a alfabetizar (catequizar) tanto crianças quanto adultos indígenas em uma intensa ação cultural e educacional, a fim de propagar a fé católica juntamente com o trabalho educativo.

Entretanto, com a chegada da família real e consequente expulsão dos Jesuítas no século XVIII, a educação de jovens e adultos entra em falência, pois a responsabilidade pela educação acaba ficando às margens do império (STRELHOW, 2010).

Em 1934, o governo cria o Plano Nacional de Educação que estabeleceu como dever do Estado o ensino primário integral, gratuito, de frequência obrigatória e extensiva para adultos como direito constitucional (FRIEDRICH et.al, 20Io).

A partir daí, mobilizações e lutas deram origem a seminários, congressos e campanhas com o objetivo de erradicar o analfabetismo. Depois de muitas idas e vindas, entre elas, destaca-se o Movimento Brasileiro de Alfabetização (MOBRAL) criado em 1967 durante o período da ditadura militar. O Ensino Supletivo, criado pela Lei de Diretrizes e Bases da Educação Nacional (no. 5.692/7I) e em 1974, o MEC desenvolveu a criação dos CES (Centros de Estudos Supletivos) que substituíram o MOBRAL.

Com o surgimento da nova Lei de Diretrizes e Bases da Educação Nacional (LDB) (no. 9.394/96), que reafirma o direito dos jovens e adultos trabalhadores ao ensino básico e o dever público de sua oferta gratuita, estabelecendo responsabilidades aos entes federados através da identificação e mobilização da demanda, com garantia ao acesso e permanência (BRASIL, 1996).

Em 2003 o Governo Federal criou a Secretaria Extraordinária de Erradicação do 
Analfabetismo, lançando então o Programa Brasil Alfabetizado (PBA), que incluía o Projeto Escola de Fábrica voltado para cursos de formação profissional, o PROJOVEM com enfoque central na qualificação para o trabalho e a implementação de ações comunitárias, e o Programa de Integração da Educação Profissional ao Ensino Médio para Jovens e Adultos (PROEJA). Já em 2007 o Ministério da Educação (MEC) aprova a criação do Fundo de Desenvolvimento da Educação Básica (FUNDEB), passando, todas as modalidades de ensino, a fazer parte dos recursos financeiros destinados à educação (BRASIL, 2007).

\section{I A EJA PARA EDUCAÇÃO INCLUSIVA}

A Educação de Jovens e Adultos é constituída por um grupo vulnerável que está sob risco de exclusão social, econômica e laboral, no caso das pessoas com deficiências esse risco de exclusão é ainda maior. Nas duas últimas décadas a legislação brasileira criou diversas leis que preveem o direito social, econômico e laboral, também a intersetorialização no âmbito da saúde e da educação, que não saíram do papel.

A Política Nacional de Educação Especial na Perspectiva da Educação Inclusiva tem como objetivo o acesso, a participação e a aprendizagem dos estudantes com deficiência, transtornos globais do desenvolvimento e altas habilidades/superdotação nas escolas regulares, orientando os sistemas de ensino para promover respostas às necessidades educacionais, garantindo:

- Transversalidade da educação especial desde a educação infantil até a educação superior;

- Atendimento educacional especializado;

- Continuidade da escolarização nos níveis mais elevados do ensino;

- Formação de professores para o atendimento educacional especializado e demais profissionais da educação para a inclusão escolar;

- Participação da família e da comunidade;

- Acessibilidade urbanística, arquitetônica, nos mobiliários e equipamentos, nos transportes, na comunicação e informação; e

- Articulação intersetorial na implementação das políticas públicas.

Algumas pessoas com deficiência não fazem parte da sociedade, o que significa um retrocesso no aprendizado, visto que a convivência da qual são privados, prejudica a aprendizagem que é mediada pelas relações humanas e pelas experiências com o meio, como expressa Vigotski:

Primeiro no nível social, e, depois, no nível individual; primeiro entre pessoas (interpsicológica), e, depois, no interior da criança (intrapsicológica). Isso se aplica igualmente para atenção voluntária, para a memória lógica e para a formação de conceitos. Todas as funções superiores originam-se das relações reais entre indivíduos 
humanos. (Vigotski. 1998, p.75)

O Censo Escolar 2018 revela avanços também na educação especial. O número de matrículas de alunos com deficiência, transtornos globais do desenvolvimento e/ou altas habilidades/superdotação em classes comuns (incluídos) ou em classes especiais exclusivas chegou a I,2 milhão em 2018, um aumento de 33,2\% em relação a 2014. Esse aumento foi influenciado pelas matrículas de ensino médio que dobraram durante o período. Considerando apenas os alunos de 4 a 17 anos da educação especial, verifica-se que o percentual de matrículas de alunos incluídos em classe comum também vem aumentando gradativamente, passando de 87,1\% em 2014 para 92,1\% em 2018.

De acordo com dados pesquisados do Censo Escolar de 2018, das mais de 45 milhões de pessoas que têm deficiência, ou seja, $24 \%$ da população brasileira, desses apenas I,2 estão matriculados na Educação Básica, enquanto que o número de alunos matriculados no país, passam dos 48 milhões. A maioria dos alunos com deficiência jovens e adultos estão inseridos no Ensino Fundamental, na EJA eles representam I,99\% do quantitativo total de matriculas, que era de 3.273.668. A maioria dos jovens e adultos com deficiência estão matriculados no Ensino Fundamental e as dificuldades para usufruírem dessa modalidade, começa com o horário noturno, uma vez que, assim precisa ser para atender a necessidade dos que trabalham durante o dia, mas no caso dos Alunos com Deficiências - $\mathrm{AcD}$, que em sua maioria não têm vida laboral, esse horário torna-se inconveniente, precisaria ser matutino ou vespertino, pois os pais se sentem inseguros em enviar seus filhos e ainda, há a questão da medicação e da rotina de dormir cedo desses indivíduos.

Segundo Werneck (2010, p. I), "As escolas têm que esquecer a ideia de que o aluno tem que se adaptar a ela. Pelo contrário elas devem tornar-se o meio mais favorável para o aluno, dando-lhes recursos para enfrentar os desafios.

\subsection{METODOS, ESTRATÉGIAS E POSSIBILIDADES DE ENSINO APRENDIZAGEM}

A escola é limitada para o ensino e aprendizagem global desses alunos, é preciso, ultrapassar seus muros para fazê-los conhecer e desfrutar de outros ambientes enriquecedores para os seus saberes. $O$ aluno jovem e adulto com deficiência, em sua maioria, passou mais tempo que o regulamentado no Ensino Fundamental, e um número significativo deles não aprendeu a ler e escrever, ou aprendeu pouco do que deveria ter aprendido. $\mathrm{Na}$ EJA as aprendizagens precisam fazer sentido para suas vidas. Temas como sexualidade e métodos contraceptivos serão, para muitos deles, mais relevantes do que aprender a escrever o nome, na fase adulta. Aprendizagens que eles possam utilizar imediatamente em suas vidas e façam sentido para eles, modificando suas vidas, fazendo-os se sentirem pessoas de valor, com independência. O docente que media aprendizagem desse público precisa ser e está motivado a ensinar e acreditar que seu aluno é capaz, não enxergar a deficiência, mas um sujeito com habilidades e 
talentos que precisam ser explorados, independente da deficiência. Trabalhar evitando que o aluno erre, isso vai mantê-lo motivado, o confronto do erro pode levar à frustração e desmotivação. $O$ interessante seria, de acordo com o grau da sua dificuldade facilitar para que ele consiga realizar a atividade, dá o apoio necessário e gradativamente ir tirando o apoio. Focando nas suas possibilidades, mas sempre estabelecendo uma relação entre o que ele já sabe, o que ele precisa aprender.

Na Pedagogia, utilizando o Modelo Social de Educação o aluno é o centro do processo de ensino e aprendizagem e é visto como sujeito de direitos, capaz que possui limites impostos pelo meio que o cerca. A chave para fazer a efetivação do ensino, é retirar as barreiras que estejam impedindo a aprendizagem. Essas barreiras podem ser de acessibilidade, atitudinal, por exemplo, se não acreditar na capacidade do educando jovem e adulto com deficiência, não demandará empenho em trabalhar o seu potencial ao máximo. Uma educação pautada em prol do desenvolvimento humano do educando fazendo valer seus talentos suas habilidades.

Mittler (2003), afirma que o modelo social da deficiência está baseado na ideia de que a escola e suas instituições, é que são discriminadoras, opressivas e incapacitantes. Portanto é necessário buscar a remoção dos obstáculos existentes à participação das pessoas com deficiências na vida em sociedade, consequentemente, para a mudança institucional, de regulamentos e de atitudes que produzem e mantêm a exclusão.

Nas tantas alternativas do que ensinar, é preciso versar por um olhar individualizado que enfoque no educando e na sua necessidade, permitindo seu acesso ao aprendizado tirando as barreiras que o impedem de se concretizar. Pensando no sujeito jovem e adulto com deficiência que vai-se ensinar, pois diferem em modo como aprendem, no conteúdo que necessitam assimilar, nos recursos que necessitam para conseguir realizar a atividade, na especialidade do recurso humano para saber usar o recurso instrumental, diferem também em grau de saberes, em grau de comprometimento mesmo compartilhando do mesmo diagnóstico, enfim, como seres únicos, eles diferem, e ainda, questiona- se: Para quem ensinar? $\mathrm{O}$ que ensinar? Como ensinar? E para quê ensinar? Levando sempre em consideração as especificidades de quem irá aprender. (LEBLANC, 1992).

\subsection{CURRÍCULO FUNCIONAL NATURAL - CFN}

O Currículo Funcional Natural é uma proposta metodológica, um conjunto de instruções e informações que reúnem não apenas uma prática a ser desenvolvida em sala de aula, como também uma filosofia e um conjunto de procedimentos.

Desenvolvido na década de 70 por um grupo de pesquisadores na universidade do Kansas, Estados Unidos para ser utilizado em crianças pequenas com 
desenvolvimento típico para desenvolver as habilidades de independência $e$ criatividade.

$\mathrm{Na}$ década de 8o, esse currículo foi levado para o Centro Ann Sullivan, por uma parceria entre as doutoras Liliana Mayo e Judith Leblanc. A equipe do Centro modificou e adaptou o currículo para ser trabalhado com pessoas com necessidades educacionais especiais (SUPLINO, 2005).

Esse currículo é programado de forma individualizada, de acordo com a realidade e necessidades de cada aluno, essa individualização, segundo Leblanc (I992, p. 2), deve estar baseada em:

- As necessidades atuais e futuras do aluno como o determina seu meio de vida;

- Informação e as habilidades que o aluno precisa apreender logo, de acordo com análise do que ele já tenha aprendido;

- As habilidades e incapacidades dos alunos, os quais estão determinados pela ação da resposta anterior do aluno nos meios educacionais.

Além disso, cada programa educacional deve incluir os mais eficazes planos e procedimentos de ensino para cada aluno e também uma avaliação contínua do êxito e do fracasso desses procedimentos e dos objetivos elencados para cada aluno. (LEBLANC,1992). Segundo a mesma autora acima, tal currículo deveria ser também, funcional, natural, divertido e proposto para ocasionar o menor número de erros possível. Suplino (2005) traz que para se utilizar o CFN existem alguns princípios norteadores:

- A pessoa como Centro: ou seja, a pessoa com necessidades educacionais especiais deve ser respeitada e tratada como qualquer outra pessoa, olhando para ela além da deficiência, enxergando o ser humano que existe apesar das limitações.

- Concentração nas habilidades: a ação/atenção deve estar concentrada naquilo que a pessoa com alguma deficiência pode fazer, naquilo que ela faz de bom, olhando as habilidades e as possibilidades.

- Todos podem aprender: as pessoas com necessidades educacionais especiais podem aprender, porém cada um aprende de um jeito e em um ritmo e cabe ao professor analisar e selecionar a melhor forma de ensinar.

- A participação da família no processo de aprendizagem: "A filosofia do CFN vê a participação da família no processo educacional da pessoa especial como peça fundamental para o avanço da mesma." (SUPLINO, 2005, p.4I) Deve-se ter um intercâmbio e uma parceria entre a instituição e a família, para que assim as técnicas de ensino sejam compartilhadas e os alunos/filhos consigam generalizar as habilidades apreendidas entre os ambientes (casa/escola).

\subsection{O DECRETO LEI $\mathrm{N}^{\circ} 03$ DE o7 DE JANEIRO DE 2008, TRANSIÇÃO PARA A VIDA ATIVA COM CURRICULO ESPECÍFICO INDIVIDUAL,}




\title{
COMO MODELOS DE INTERVENÇÃO EDUCACIONAL
}

\author{
Artigo 14..$^{\circ}$ \\ Plano Individual de Transição \\ I - Sempre que o aluno apresente necessidades educativas especiais de \\ carácter permanente que o impeçam de adquirir as aprendizagens e \\ competências definidas no currículo deve a escola complementar o programa \\ educativo individual com um plano individual de transição destinado a \\ promover a transição para a vida pós-escolar e, sempre que possível, para o \\ exercício de uma atividade profissional com adequada inserção social, \\ familiar ou numa instituição de carácter ocupacional. \\ 2 - A concretização do número anterior, designadamente a \\ implementação do plano individual de transição, inicia-se três anos antes da \\ idade limite de escolaridade obrigatória, sem prejuízo do disposto no artigo \\ anterior. \\ 3 - No sentido de preparar a transição do jovem para a vida pós-escolar, \\ o plano individual de transição deve promover a capacitação e a aquisição de \\ competências sociais necessárias à inserção familiar e comunitária. \\ 4 - O plano individual de transição deve ser datado e assinado por todos \\ os profissionais que participam na sua elaboração, bem como pelos pais ou \\ encarregados de educação e, sempre que possível, pelo próprio aluno.
}

Artigo 21. $\mathrm{o}$

Currículo Específico Individual

I - Entende-se por currículo específico individual, no âmbito da educação especial, aquele que, mediante o parecer do conselho de docentes ou conselho de turma, substitui as competências definidas para cada nível de educação e ensino.

2 - O currículo específico individual pressupõe alterações significativas no currículo comum, podendo as mesmas traduzir-se na introdução, substituição e ou eliminação de objetivos e conteúdos, em função do nível de funcionalidade da criança ou do jovem.

3 - O currículo específico individual inclui conteúdos conducentes à autonomia pessoal e social do aluno e dá prioridade ao desenvolvimento de atividades de cariz funcional centradas nos contextos de vida, à comunicação e à organização do processo de transição para a vida pós-escolar.

4 - Compete ao conselho executivo e ao respectivo departamento de educação especial orientar e assegurar o desenvolvimento dos referidos currículos.

O Decreto de Lei $N^{\circ} 03 / 2008$ de 07 de janeiro que estabelece a elaboração de Planos Individuais de Transição e sua obrigatoriedade, três anos antes do término da escolaridade obrigatória. É preciso definir quais as necessidades do educando com o Currículo Educacional Individual para desenvolver estratégias para o Plano Individual de Transição (PIT).

A escola precisa acreditar na capacidade de todos os alunos, independente do grau de limitação e trabalhar suas necessidades educacionais com vistas ao que seja útil às suas vidas trazendo mudanças das dificuldades abarcadas pela deficiência para que gradativamente esse indivíduo possa usufruir da vida em sociedade, com as obrigações 
que ela contém. A família, por sua vez precisa repensar as expectativas mínimas que tem a respeito do jovem e adulto com deficiência severa, é preciso expor e fazê-los refletirem para que percebam suas habilidades e potencial.

\section{O QUE ENSINAR E PARA QUE ENSINAR?}

Atualmente, preconiza-se nas escolas o Modelo Pedagógico social que foca no educando com deficiência e não na deficiência, como instituía o modelo médico. Jovens e adultos estão inseridos em salas regulares, recebendo aprendizagens que, quando a concebem, não têm no quê, nem como aplicar em seu cotidiano, são aprendizagens que não acrescentam muito às suas vidas. São indivíduos que passaram toda uma vida escolar sem muitos ganhos, e que na vida adulta precisam de uma aprendizagem que neles produzam o sentimento de que estão desenvolvendo em seu entendimento de mundo, sua independência, e condições de escolhas, fazendo com que não só os outros, mas eles mesmos percebam seu crescimento, e assim possam buscar seus interesses e fazer suas escolhas.

Mendes (2006, p. 397) aponta que, apesar dos avanços na política de expansão e garantia do ensino na escola regular, os alunos com deficiência “[...] não estão necessariamente recebendo uma educação apropriada, seja por falta de profissionais qualificados ou mesmo pela falta generalizada de recursos”. Dessa forma, é necessário pensar sobre a oferta do ensino para as pessoas com deficiência no ensino regular, procurando refletir se são oferecidas condições necessárias para o desenvolvimento desse público, visto que suas demandas são específicas.

A escola pode aplicar Projetos de Transição para a Vida Ativa - TVA que promova transição para situações de integração na vida social e profissional. Uma transição pós-escola para todo educando com deficiência de caráter permanente que não consiga adquirir as aprendizagens delineadas no currículo. Cabe a escola complementar o PEI (Plano Educacional Individual) com o PIT (Plano Individual de Transição) para iniciar essa transição.

Soriano (2006, p.24) conceitua o PIT como:

Um instrumento, uma ferramenta, sob a forma de documento no qual é registrado o passado, presente e futuro desejado do jovem: condições familiares, história médica, tempos livres, valores e background cultural e ainda, informação sobre sua educação e formação.

A TVA vai preparar o educando jovem e adulto para circular de forma independente nos diversos ambientes da comunidade em que está inserido, com menos restrição possível. É preciso estimular a transferência do que lhes fora

ensinado, criando oportunidades extraescolares. As Estratégias Curriculares e os conteúdos escolares devem ser flexibilizados e relacionados às características dos estudantes. 
Projetos de palestras com recursos digitais, de anatomia, teatro de bonecos e outros, para incrementar o interesse dos educandos, com temas de relevância para situá-lo em seu contexto idade/mundo, pois são adultos e não crianças, e de acordo com suas necessidades precisam ser instruídos com aprendizagens que traga qualidade de vida e que sejam utilizados no momento, para uma transição de vida autônoma. Há jovens e adultos com deficiência que já têm um entendimento de namoro, sexualidade e não são orientados sobre o assunto, há outros que não entendem sobre o tema, é preciso trazer à baila questões que são naturais da vida deles e do seu cotidiano. Uma oficina de cozinha, onde eles possam coletivamente fazer uma receita e mostrar suas habilidades. São situações que muitos não vivenciam, por terem a família que faz tudo pra eles, isso precisa ser trabalhado na EJA e, é essencial o envolvimento da família, para que percebam que seus filhos são capazes e podem ter uma vida autônoma. É preciso que se pense a EJA numa perspectiva de desenvolvimento humano. Deveria ser do interesse do Poder Público promover uma educação que realmente faça a diferença na vida desses educandos, porque eles envelhecem e seus pais morrem. Qual será o destino deles? Se forem indivíduos autônomos terão maiores chances de sobreviverem. $O$ conceito de Educação ao Longo da Vida, é a direção para uma aprendizagem contínua que permita ao educando, aprender no seu tempo e ter acesso a saberes que sejam significativos para uma vida digna e inclusiva. Numa sociedade onde somente os fortes sobrevivem, eles precisam ser direcionados pela escola formal, para uma vida independente e cidadã, para isso a continuidade dos estudos ao longo da vida é essencial. Sua terminalidade se encerra onde for possível, onde ele quiser; suas necessidades, interesses, sonhos e motivações irão dizer quando encerrar suas vidas acadêmicas.

\section{METODOLOGIA}

O tipo de pesquisa adotada foi de Abordagem Qualitativa. De acordo com Gephart (2004), a pesquisa qualitativa fornece uma narrativa da visão da realidade dos indivíduos, sendo, portanto, descritiva. Ela ainda dá uma ênfase aos detalhes situacionais, permitindo uma boa descrição dos processos.

Em razão da escassez de pesquisas sobre o tema, o presente estudo caracteriza-se como um estudo exploratório. Geralmente, o estudo é exploratório quando há pouco conhecimento sobre o tema a ser abordado (Aaker et al., 2004), como ocorre nesta pesquisa.

Para os Procedimentos Bibliográficos e Documental teve-se como Instrumento de Coleta as Fontes Bibliográficas e Estatísticas.

\section{DISCUSSÃO E RESULTADOS}

Compreende-se que nos limites desta pesquisa não foi possível aprofundar os estudos sobre os métodos e estratégias de ensino e aprendizagem, permitindo sua continuidade futura. 
A pesquisa tem sua relevância em provocar a reflexão da inclusão de jovens e adultos que estão inseridos em escolas regulares no Ensino Fundamental quando por ele já passaram, e durante a sua escolaridade não obtiveram êxito de aprendizagem, e na EJA, em horários diurno / noturno como o ideal didático para idade deles, com oferta de aprendizagens que os instrua para a vida. $O$ que, para quê e como ensinar a esse educando? Quais projetos a escola pode desenvolver para trazer aprendizagens significativas que proporcionem autonomia e seja relevante para vida desse educando?

Conforme a Declaração de Salamanca:

Como preconiza a Declaração de Salamanca, na premissa $18^{\circ}$ Atenção especial deveria ser prestada às necessidades das crianças e jovens com deficiências múltiplas ou severas. Eles possuem os mesmos direitos que outros na comunidade, à obtenção de máxima independência na vida adulta e deveriam ser educados neste sentido, ao máximo de seus potenciais.

Temos que ter em mente O QUÊ vamos ensinar a nossos alunos. A pergunta necessária é: Terá alguma utilidade para sua vida? Se a resposta for negativa, melhor buscarmos outra habilidade para ensinar.

Um Processo de Ensino e Aprendizagem Ocasione o Menor Número Possível de Erros - Muitos de nossos alunos vêm de uma longa história em instituições de ensino. Ao longo de sua vida escolar não foram poucas as situações nas quais as tentativas de aprender resultaram em frustrações. Em muito dos casos, os alunos e suas famílias escutaram que os mesmos jamais iriam aprender.

A promoção de uma aprendizagem significativa independe da limitação que o aluno com deficiência intelectual possa ter, ainda que a criança possua subsunçores limitados, pode fazer deles uma "ponte" para novos conhecimentos, cabendo ao professor fazer a diferenciação neste processo de aprendizagem diferenciado. Conforme $\operatorname{MEC}(1999)$,

[...] nem todos os alunos e alunas se apresentam com a mesma bagagem, da mesma forma, no que se refere às aprendizagens já por eles efetivadas. Todos os alunos e alunas têm capacidades, interesses, ritmos, motivações e experiências diferentes, que mediatizam seu processo de aprendizagem, fazendo que seja único e diferente, em cada caso.

É comum encontrar-se pessoas portadoras de retardo severo ou autismo que alcançaram a idade adulta sem, no entanto, serem capazes de realizar tarefas mínimas relacionadas a autocuidados ou auto proteção, por exemplo. Os pais encontram-se em um impasse: de um lado, temem por seus filhos, na medida em que não os consideram capazes de executar nenhuma tarefa de maneira independente, passando, então, a tomar as iniciativas realizando todas as coisas por eles. Alguns desses educandos chegam à escola em diferentes níveis de ensino, alguns sem autonomia mínima, e a escola, por sua vez, encontra-se num impasse, porque se por um lado procura encontrar 
tarefas que sejam adequadas às idades de seus alunos, quando da elaboração dos currículos, na maioria das vezes, centra-se em atividades acadêmicas, tarefas que, muitas vezes, estão completamente distantes da realidade vivida pelos alunos e que, portanto, tornam as aulas enfadonhas fazendo com que a frequência de comportamentos inadequados aumente.

A deficiência mental coloca em xeque a função primordial da escola comum que é a produção do conhecimento, pois o aluno com essa deficiência tem uma maneira própria de lidar com o saber que, invariavelmente, não corresponde ao ideal de escola. $\mathrm{Na}$ verdade, não corresponder ao esperado pode acontecer com todo e qualquer aluno, mas os alunos com deficiência mental denunciam a impossibilidade de atingir esse ideal, de forma tácita. Eles não permitem que a escola dissimule essa verdade. As outras deficiências não abalam tanto a escola comum, pois não tocam no cerne e no motivo da sua urgente transformação:

entender a produção do conhecimento acadêmico com uma conquista individual. (MEC, SEED, 2007, p.12)

Faz-se necessário, considerar a importância da criação de programas que ensinem habilidades adaptativas a jovens e adultos com deficiências não só dentro de escolas, mas também em suas residências, instituições e comunidades, para que se tornem mais independentes, aprendam e convivam com comportamentos mais adequados para a sociedade. É também urgente que os Sistemas de ensino invistam em Formação Continuada para profissionais da educação ampliando as possibilidades de Metodologias e Estratégias de Ensino que venham a somar positivamente no desenvolvimento dos Alunos com deficiência- $A c D$, e que proporcione uma estrutura de ambiente de trabalho adequado e equipado com os recursos necessários que estimule e motive fazendo com que se mantenham produzindo continuamente, de maneira a contribuírem significativamente para mudar a realidade desses educandos.

O Currículo Funcional/Natural expressa em seu nome qual é a sua amplitude e a que se destina. A palavra funcional se refere à maneira como os objetivos educacionais são escolhidos para o aluno enfatizando que aquilo que ele vai aprender tenha utilidade para sua vida a curto ou a médio prazo. A palavra natural diz respeito aos procedimentos de ensino, ambiente e materiais os quais deverão ser o mais semelhantes possível aos que encontramos no mundo real. (LeBlanc, 1992) Os objetivos centrais da aplicação do Currículo Funcional/Natural são, nas palavras de LeBlanc "tornar o aluno mais independente e produtivo e também mais aceito socialmente."

\section{CONSIDERAÇÕES FINAIS}

Com desenvolvimento desta pesquisa, contatou-se que os jovens e adultos com deficiência, em sua maioria, estão matriculados nos Anos Finais do Ensino Fundamental e não na Educação de Jovens e Adultos como seria o adequado para suas 
fases de vida, e não têm recebido um ensino aprendizagem que traga mudanças significativa de saberes e autonomia. Como é o caso do filho da colega, que se encontra inserido em sala de aula, e se for relacionar seu

aprendizado a idade que tem, não houve uma evolução significativa em seus saberes para uma vida autônoma.

A EJA na perspectiva da Educação Inclusiva precisa modificar sua atuação para responder as necessidades do jovem e adulto com deficiência, para articular-se com a família na efetivação desse processo, envolver a comunidade e firmar parcerias que proporcione acesso à formação no que o educando for vocacionado, acesso ao lazer e ao trabalho, à participação social e à vida autônoma, explorando e desenvolvendo ao máximo o potencial de cada indivíduo.

Diante disso a pesquisa teve o seguinte Objetivo Geral: Quais Metodologias, Estratégias e Aprendizagens, Contribuirão para Fazer a Diferença na Vida do Educando Jovem e Adulto com deficiência na Modalidade EJA? Tendo-se por resposta, uma metodologia que olhe para o educando como indivíduo peculiar, capaz e não para as limitações que a deficiência lhe impõe e que podem ser superadas quando as barreiras são suprimidas.

Os Objetivos Específicos que mediaram o Objetivo Geral foram:

No país a maioria dos jovens e adultos com deficiência estão dentro das salas de aula no Ensino Fundamental ou na EJA, neste último, em horário diurno ou noturno. No Ensino Fundamental estão em oposição ao adequado, a EJA, ideal à fase adulta que se encontram. Os conteúdos e as aprendizagens ministrados não promovem a autonomia e funcionalidade em seus contextos de vida.

Faz-se necessários aprendizados que sejam úteis a pequenos e médios prazos para terem o fim de ir promovendo o grau de autonomia e independência que precisam para engatarem numa vida o mais emancipadora possível.

Metodologias centradas no aluno e nas suas especificidades com atividades significativa, que dê sentido e significado ao seu contexto de vida, suprimindo as dificuldades que o meio impõe, para impulsionar sua inclusão social dentro e fora da escola. Permitindo assim, que os Objetivos Específicos propostos fossem realmente alcançados.

Expondo Dados Bibliográficos e o Decreto Lei $n^{\circ} 03 / 2008$ na pesquisa, foi possível realizar o Método Hipotético Dedutivo, verificou-se a confirmação da hipótese de que a adoção do Currículo Funcional Natural e do Programa de Transição para a Vida Ativa na aprendizagem educandos jovens e adultos, ainda

que sejam métodos que já existem há anos, apresentam resultados significativos dos saberes, da autonomia e da inserção social em diversos ambientes da sociedade, inclusive no profissional.

Os dados foram coletados através de Fontes Bibliográficas, dados Estatísticos do Inep, e palestras sobre Currículo Funcional Natural e Transição para Vida Ativa 
realizadas no Youtube pelas Profas. Dras. Iasmin Zanchi Boueri- UFPR no dia 22 de novembro de 2018, e Prof ${ }^{\mathrm{a}}$ Windyz B. Ferreira, PhD (vídeo criado para o IV Encontro de Diversidade e Inclusão de Currículo Funcional e Transição para Vida Ativa, em 08/ı2/2017); Exemplo de Aplicação de Currículo Funcional, e Modelos de Deficiência e Currículo Funcional em 30/07/17; Educação de Jovens e Adultos para Pessoas com Deficiência em 05/II/2017 (vídeo criado para o IV Encontro Internacional sobre Educação de Jovens e Adultos). Universidade do Minho, Braga, Portugal.

O trabalho tem sua relevância social e acadêmica, em sugerir um ensino pautado numa aprendizagem de prática imediata para o dia a dia do educando, aquilo que realmente fará a diferença em sua vida, promovendo resultados em um pequeno e médio prazo. Também em propiciar reflexões acerca da inclusão de jovens e adultos no sistema de ensino. O Ensino Fundamental é adequado ao jovem e adulto com deficiência, e quais as aprendizagens eles precisam conceber para terem seus saberes e construídos?

Durante a metodologia proposta, percebeu-se que o trabalho poderia ter sido ampliado com a realização de uma pesquisa de campo, que coletasse amostras da população de pelo menos três lócus, para reunir dados mais precisos sobre o número de jovens e adultos que estudam no Ensino Fundamental, Médio, na EJA, e recolher respostas acerca do que estão aprendendo e o que gostariam de aprender. Indagar também, os docentes acerca do que ensinam e quais aprendizagens acham necessárias para esse público. Encontrando-se em período de Pandemia, inviabilizou-se a Pesquisa de Campo.

A escola precisa acreditar na capacidade de todos os alunos, independente do grau de limitação e trabalhar suas necessidades educacionais com vistas ao que seja útil às suas vidas trazendo mudanças das dificuldades abarcadas pela deficiência para que gradativamente esses indivíduos possam usufruírem da vida em sociedade, com as obrigações que ela contém. A família,

por sua vez precisa repensar as expectativas mínimas que tem a respeito do jovem e adulto com deficiência severa, é preciso expor aos pais e fazê-los refletirem para que percebam suas habilidades e potencial. A escola enquanto instituição limitada, deve buscar parcerias e reunir esforços conjuntos para que esses indivíduos tenham uma educação escolar transformadora que ultrapassem os muros os muros da escola.

\section{REFERÊNCIAS}

FRIEDRICH et.al. Trajetória da Escolarização de Jovens e Adultos no Brasil: De plataformas de Governo as Propostas Pedagógicas Esvaziadas. Ensaio: avaliação das políticas públicas educacionais. Rio de Janeiro, v. I8, n. 67, p. 389-410, abr./jun. 2010.

SUPLINO, M. Currículo Funcional Natural: guia prático para a educação na área de autismo e deficiência mental - Brasília: Secretaria Especial dos Direitos Humanos, 
Coordenadoria Nacional para a Integração da Pessoa Portadora de Deficiência; Maceió: ASSISTA, 2005. P.: 2I cm. (Coleção de Estudos e Pesquisa na Área da Deficiência; v. II). $73 \mathrm{p}$.

LeBlanc, J. M. El Curriculum Funcional em la educación de la persona com retardo mental. Trabalho apresentado na ASPANDEM, Mallagra. España, 1992. Tradução: ALMEIDA, M. A.; BOUERI, I.Z.

MENDES, E. G. A radicalização do debate sobre inclusão escolar no Brasil. Revista Brasileira de Educação, Rio de Janeiro, v. II, n. 33, p. 387-405, dez. 2006.

SORIANO, Victoria. Planos individuais de transição: apoiar a transição da escola para o emprego. European Agency for Development in Special Needs Education, 2006.

GEPHART, R.P. Qualitative research and the Academy of Management Journal. Academy of Management Journal, v. 47, n. 4, p. 454-462, 2004.

AAKER, D.A. et al. Pesquisa de marketing. São Paulo: Atlas, 2004.

MEC / BRASIL. Parâmetros Curriculares Nacionais: Adaptações Curriculares. Estratégias para a Educação de Alunos com Necessidades Educacionais Especiais. Brasília, MEC/ SEF/SEP, 1999.

CURRÍCULO FUNCIONAL NATURAL, GUIA PRÁTICO PARA A EDUCAÇÃO NA ÁREA DE AUTISMO E DEFICIÊNCIA MENTAL. Disponível em:

<http://feapaesp.org.br/material_download/566_Livro\%20Maryse\%20Suplyno\% 20$\% 20$ Curriculo\%2oFuncional\%20Natural.pdf/>. Acesso em: io de novembro de 2020.

INDEPENDÊNCIA REFORÇADA. Revista Deficiência Intelectual, 2017. Disponível em: <https://www.ijc.org.br/pt-br/sobre-deficiencia-

intelectual/publicacoes/Documents/DI_nII_baixa.pdf/>. Acesso em: in de novembro de 2020 .

\section{A TRAJETÓRIA HISTÓRICA DA EJA NO BRASIL E SUAS PERSPECTIVAS}

NA ATUALIDADE? SIC - Seminário de Iniciação Científica, 2or6. Disponível em: $<$ ifnmg.edu.br/arquivos/2016/proppi/sic/resumos/e4eoc388-a724-45cb46eza7oafa64.pdf/>. Acesso em: 12 de novembro de 2020 .

BRASIL. LEI № 3/2008,DE 7 DE JANEIRO. Disponível em: 
<https://dre.pt/pesquisa/-/search/386871/details/normal?q=Decreto-

Lei+n.\% $\mathrm{C}_{2} \% \mathrm{BA} \% 203 \% 2 \mathrm{~F} 2008 \% 2 \mathrm{C} \% 20 \mathrm{de}+7+\mathrm{de}+\mathrm{janeiro} />$. Acesso em: 12 de novembro de 2020 .

\section{CRESCE O NÚMERO DE ESTUDANTES COM NECESSIDADES ESPECIAIS.}

Disponível em: <https://agenciabrasil.ebc.com.br/educacao/noticia/2org- or/cresce-onumero-de-estudantes-com-necessidades-especiais/>. Acesso em: 12 de novembro de 2020 .

CURRÍCULO FUNCIONAL NATURAL - ANÁlisE DE TESES E DISSERTAÇÕES DO PROGRAMA DE PÓS-GRADUAÇÃO EM EDUCAÇÃO ESPECIAL DA UFSCAR A PARTIR DE 2ooo. Disponível em:

<http://www.uel.br/eventos/congressomultidisciplinar/pages/arquivos/anais/2oI 3/ATi4-2013/ATi4-or6.pdf/>. Acesso em: I2 de novembro de 2020.

MATRÍCULAS NA EDUCAÇÃO DE JOVENS E ADULTOS CAEM; 3,3 MILHÕES DE ESTUDANTES NA EJA EM 2org. Disponível em: <http://inep.gov.br/artigo/-/asset_publisher/B4AQV ${ }_{9 z} \mathrm{FY}_{7} \mathrm{Bv} /$ content/matriculasna-educacao-de-jovens-e-adultos-cai-3-3-milhoes-de-estudantes-na-eja-em2019/21206\#: :text=Fevereiro\%20de\%202020-

,Matr\%C3\%ADculas\%2ona\%2oeduca\%C3\%A 7\%C3\%A30\%2ode\%2ojovens\% 20e\%20adultos\%20caem\%3B\%203\%2C3,jovens\%2,oe\%20adultos\%2o(EJA).\&t ext $=\mathrm{A} \% 20 \mathrm{oJ}$ A\%2otem\%203.273.668\%2oestudantes\%2omatriculados/>.

Acesso em: 12 de novembro de 2020 .

\section{POLÍTICA NACIONAL DE EDUCAÇÃO ESPECIAL NA PERSPECTIVA DA}

EDUCAÇÃO INCLUSIVA. Disponível em:

$<$ http://portal.mec.gov.br/index.php?option=com_docman\&view =download \&alia $s=16690$-politica-nacional-de-educacao-especial-na-perspectiva-da-educacao- inclusiva05122014\&Itemid=30192/ >. Acesso em: 13 de novembro de 2020.

PESSOAS COM DEFICIÊNCIA. Disponível em:

<educa.ibge.gov.br/jovens/conheca-o-brasil/populacao/20551-pessoas-comdeficiencia.html/>. Acesso em: 13 de novembro de 2020 .

PROGRAMA BRASIL ALFABETIZADO (PBA). Disponível em: 
<http://www.fnde.gov.br/component/k2/item/II522-programa-brasil- alfabetizado$\mathrm{pba} />$. Acesso em: 13 de novembro de 2020.

BRASIL. LEI №. 9.394, DE 20 DE DEZEMBRO DE 1996. Estabelece as

diretrizes e bases da educação nacional. Diário Oficial da União, Brasília, DF, 20 dez. 1996.

CENSO ESCOLAR 2018 REVELA CRESCIMENTO DE I8\% NAS MATRÍCULAS EM TEMPO INTEGRAL NO ENSINO MÉDIO. Disponível em:

$<$ http://portal.inep.gov.br/artigo/-

/asset_publisher/B $4 \mathrm{AQV}_{92} \mathrm{FY}_{7} \mathrm{Bv} /$ content/censo-escolar-2or8-revela- crescimentode-I8-nas-matriculas-em-tempo-integral-no-ensino-

medio/21206\#: : :text=O\%20n\%C3\%BAmero\%2ode\%2omatr\%C3\%ADculas\%2

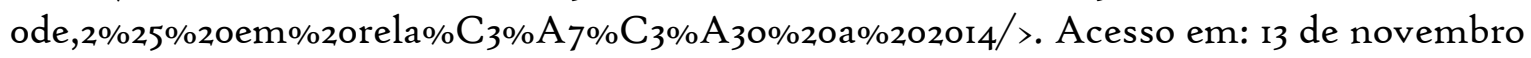
de 2020 .

CLASSIFICAÇÕES DE FINALIDADE EM PESQUISA ACADÊMICA. Disponível

em: <https://www.atenaeditora.com.br/blog/classificacoes-de-finalidade-empesquisa-

academica/\#: :text=Toda\%2opesquisa\%2oacad\%C3\%AAmica\%2ose\%2odesti na,forma\%20com\%200\%20/>. Acesso em: 13 de novembro de 2020.

STRELHOW, T. B. BREVE HISTÓRIA SOBRE A EDUCAÇÃO DE JOVENS E

ADULTOS NO BRASIL. revista HISTEDBR On-line, Campinas, n.38, p. 49-59, jun.2oro.

BRASIL. LEI № 13.632, DE 6 DE MARÇO DE 2018. Disponível em:

〈https://presrepublica.jusbrasil.com.br/legislacao/553109197/lei-13632-6- marco-2018/〉. Acesso em: 13 de novembro de 2020 .

NOGUEIRA, Rosa Maria de Freitas. TRANSIÇÃO PARA A VIDA ATIVA DE JOVENS COM NCESSIDADES EDUCATIVAS ESPECIAIS.

Educação

Especial, Ediçãon. 8. Jan, 2015 - 2016. Disponível em: 
〈https://issuu.com/iesfafe/docs/8__revista_cientifica_transi

ol/>. Acesso

em:

Acesso em: 13 de novembro de 2020 .

A IMPORTÂNCIA DA APRENDIZAGEM SIGNIFICATIVA POR MEIO DE REPRESENTAÇÕES MULTIMODAIS EM CRIANÇAS COM DEFICIÊNCIA INTELECTUAL. Disponível em:

<http://www.uel.br/eventos/semanadaeducacao/pages/arquivos/Anais/2017/An ais/Artigo/Eixo\%202\%2oEducacao\%20e\%2oDiversidade\%20e\%20Direitos\%20 Humanos/A\%20IMPORT\%20DA\%20APRENDIZ\%20SIGNIFIC\%20POR\%20M EIO\%20DE\%20REPRESENT\%2оMULTOMODAIS\%2。EM\%20CRIANCAS\%20 DEF\%2oINTELECTUAL.docx/. Acesso em: Acesso em: 13 de novembro de 2020 .

\section{O PROFESSOR PDE E OS DESAFIOS DA ESCOLA PÚBLICA}

\section{PARANAENSE. Disponível em:}

〈http://www.diaadiaeducacao.pr.gov.br/portals/cadernospde/pdebusca/produco es_pde/2010/2010_unicentro_edespecial_artigo_lurdes_bellandi.pdf/>. Acesso em: 16 de novembro de 2020 .

DECLARAÇÃO DE SALAMANCA. Disponível em:

http://portal.mec.gov.br/seesp/arquivos/pdf/salamanca.pdf/. Acesso em: 16 de novembro de 2020 .

PARECER CNE CEB $\mathrm{N}^{\circ}{ }^{\circ}$ /20oo. Disponível em:

<http://confinteabrasilmais6.mec.gov.br/images/documentos/parecer_CNE_CE B_II_2000.pdf $>$. Acesso em: 16 de novembro de 2020 . 